\title{
Avaliação do perfil dos pacientes em uma clínica odontológica universitária em relação ao conhecimento e controle das doenças periodontais
}

\author{
Profile evaluation of patients in an university dental clinic in relation to knowledge and \\ disease control periodontal
}

\author{
Ana Larice de Oliveira Sampaio ${ }^{1}$, Adriana Moucherek ${ }^{1}$, Lívia Helena de Araujo Castro \\ Nunes $^{2}$, José Carlos Elias Mouchrek Júnior ${ }^{3}$, Clélea de Oliveira Calvet ${ }^{4}$
}

\begin{abstract}
Resumo: Este estudo teve por objetivo correlacionar o estado de saúde periodontal com a higiene bucal utilizada pelos pacientes atendidos nas clínicas odontológicas de uma universidade privada e seus conhecimentos e formas de prevenção e/ou controle das doenças periodontais. Método: Nesse estudo, 30 pacientes foram escolhidos aleatoriamente e submetidos a exame clínico. Com base no Periograma, fora estabelecido o diagnóstico periodontal de cada um deles e foram aplicados questionários, investigando os seus hábitos de higiene bucal e conhecimento sobre as doenças periodontais. Resultados: os resultados demonstraram que a maioria dos indivíduos desconhecia placa bacteriana $(72,4 \%)$, gengivite e periodontite $(72,4 \%)$, tártaro, cálculo dental $(65,5 \%)$, não saberia identificar uma escova dental com características ideais $(55,2 \%)$, nem o período correto para a substituição da escova dental $(89,7 \%)$ e que a maior parcela destes pacientes não utilizava antisséptico bucal $(58,6 \%)$ e não faziam o uso do fio dental $(65,5 \%)$. Conclusão: os pacientes apresentam baixo conhecimento em relação às doenças periodontais e aos hábitos de higiene bucal. A respeito das doenças periodontais, encontra-se a prevalência da periodontite crônica nesse grupo. A participação do profissional na educação, motivação e na prevenção das doenças bucais desses pacientes é imprescindível, necessitando, assim, receber mais atenção por parte dos responsáveis pelo tratamento.
\end{abstract}

Palavras-chaves:Doenças periodontais. Clínica Odontológica da Universitária. Pacientes.

\begin{abstract}
This study aimed at correlating the state of periodontal health with oral hygiene used by patients seen in the dental clinics University and their knowledge and ways to prevent and / or control of periodontal diseases. Methods: in this study, 30 patients were randomized and underwent clinical examination. Based on Periogram outside established the diagnosis of periodontal each and were administered questionnaires, investigating their oral hygiene habits and knowledge of periodontal diseases. Results: Data showed that most individuals unaware plaque $(72.4 \%)$, gingivitis and periodontitis $(72.4 \%)$, plaque / dental calculus $(65.5 \%)$ could not identify a toothbrush with ideal characteristics $(552 \%)$, nor the correct period for the replacement toothbrush $(89.7 \%)$ and that most of these patients did not use mouthwash (58.6\%) and did the flossing (65.5\%). Conclusion: Patients have low knowledge regarding periodontal disease and oral hygiene habits. Regarding periodontal disease, is the prevalence of chronic periodontitis in this group. The involvement of the professional in education, motivation and prevention of oral disease in these patients is essential, requiring thus receive more attention from the controllers.
\end{abstract}

Keywords: Periodontal diseases. University Dental Clinic. Patients

1-Graduada do Curso de Odontologia da Universidade CEUMA

2-Docente da Universidade Ceuma

Rev. Investig. Bioméd., São Luís, 6:14-21, 2014 


\section{Introdução}

As doenças periodontais, gengivite e periodontite, são patologias causadas por microrganismos bacterianos encontrados na placa ou biofilme aderidos à superfície dentária. Portanto, pode-se considerar o biofilme dental o fator etiológico principal das doenças periodontais e, ainda, que este relaciona- se diretamente com a reação imunológica do hospedeiro, sua suscetibilidade e condições ambientais para poder desenvolver tais patologias ${ }^{1}$.

A placa dental ou biofilme dental consiste numa massa de matriz orgânica não calcificada e colonizada por inúmeros tipos de microrganismos organizados em colônias. É principalmente classificada em relação a sua localização em: placa supragengival (acima da margem gengival) e subgengival (abaixo da margem gengival) ${ }^{2}$.

A placa subgengival e a placa supragengival não se diferem apenas no quesito "posição em relação à margem gengival", mas também, em relação ao tipo de microrganismo predominante em cada uma, mostrando que existe uma especificidade local da placa. A microbiota subgengival, por exemplo, sobrevive a um ambiente anaeróbio, ou seja, com ausência de oxigênio. Espécies como Streptococcusintermedius, Peptostreptococcus micros, Porphyromonasgingivalis, Prevotella intermedia, Tannerellaforsythia e Fusobacteriumnucleatum, segundo estudos realizados, são espécies encontradas e consideradas predominantes na placa subgengival associada ao tecido e possuem grande importância na destruição tecidual ${ }^{3}$.

A gengiva, também chamada de periodonto de proteção, consiste numa parte da mucosa bucal mastigatória que envolve a porção cervical do elemento dentário, recobrindo o processo alveolar e a raiz do dente no nível da coroa e possui a função de evitar a penetração de microrganismos e agentes nocivos nos tecidos situados mais profundamente. A gengiva saudável é firme, sem sangramento, com papilas entre os dentes bem definidas e com uma tonalidade próxima do rosa 4 .

Quando o paciente não possui uma higiene bucal eficiente, começa a haver o acúmulo de placa e a sua mineralização promove a formação de cálculos nas superfícies dos dentes. A presença do cálculo e o acúmulo de uma placa ativa sobre este provocam uma inflamação gengival e sangramento durante a escovação, uso do fio dental e, muitas vezes, espontaneamente (gengivite). Pode ocorrer recessão gengival, com sensibilidade ao frio, doces e calor. Se o cálculo não for removido, a infamação progredirá, o que, posteriormente, poderá causar destruição do periodonto e até a perda do dente ${ }^{4}$.

A gengivite é caracterizada clinicamente por vermelhidão gengival, acompanhada de inchaço (sinais característicos da inflamação) e sangramento à sondagem, porém sem acometimento de osso e ligamentos periodontais. A condição dessa patologia é passível de reversibilidade e pode persistir sem posterior perda de inserção de tecido conjuntivo ${ }^{5}$.

Já a periodontite, é uma inflamação crônica que acomete gengiva, osso e ligamentos de suporte dos dentes. Nesse caso, há um aprofundamento patológico do sulco gengival por meio da migração apical do epitélio juncional. É definida como uma condição patológica multifatorial complexa, na qual envolvem os microrganismos causadores da doença, assim como a resposta imunológica do hospedeiro, que pode contribuir para a destruição do periodonto ${ }^{6-7}$.

A principal, mais econômica e eficaz forma da prevenção do aparecimento e desenvolvimento das doenças periodontais é o controle da placa 
bacteriana. Da mesma forma, a educação e a motivação dos pacientes, orientandoos em relação à higiene bucal e hábitos alimentares menos cariogênicos, informando a existência e forma de prevenção das doenças e a diferença entre um periodonto saudável e aquele acometido por alguma patologia, são formas importantes para evitar doenças periodontais e promover a saúde bucal do paciente ${ }^{8}$.

A realização dessa pesquisa justificou-se pela necessidade de ressaltar a importância do paciente: possuir uma higiene bucal eficiente, que evite 0 acúmulo do biofilme dental, sendo esse 0 fator determinante para o surgimento das doenças periodontais; possuir noções básicas a cerca da distinção entre um periodonto saudável e o acometido por uma doença periodontal, assim como suas formas de prevenção, controle e manutenção da saúde bucal.

\section{Métodos}

Esta pesquisa foi realizada nas clínicas odontológicas da Universidade Ceuma. Para essa análise, optou-se por um estudo descritivo com variáveis quantitativas. A amostra fora constituída por 30 (trinta) pacientes atendidos nas clínicas odontológicas da Universidade CEUMA, em São Luís-MA. Esses pacientes foram escolhidos aleatoriamente para a pesquisa e foram atendidos no período de agosto a novembro de 2012. Foram aplicados questionários, que indagavam a respeito de conhecimentos sobre as doenças periodontais e sobre hábitos de higiene bucal desses pacientes; e realizados exames clínicos; periograma e índice de placa de O'Leary, utilizado para classificar a higiene bucal (favorável: < 25\%). Com base nos dados colhidos na anamnese, exame clínico e periograma, fora estabelecido o diagnóstico periodontal de cada paciente de acordo com os princípios da American AcademyofPeriodontology (AAP), observando-se o nível gengival (NG), a profundidade de sondagem (PS) e o nível de inserção clínica (NIC), a presença ou não de sangramento, a presença ou a ausência de mobilidade dentária e de lesão de furca.

A pesquisa não utilizou dados que identifiquem o paciente, como nome, endereço e telefone, e o acesso a tais prontuários se deu a partir de autorização prévia, com termo de consentimento livre e esclarecido.

Os dados foram tabulados na planilha eletrônica Excel e posteriormente analisados pelo programa estatístico BioEstat, versão 5.3. As variáveis dependentes foram representadas pelo diagnóstico periodontal (gengivite ou periodontite), extensão do comprometimento periodontal (localizada ou generalizada) e gravidade da periodontite crônica (leve moderada ou avançada). As variáveis independentes englobaram: idade, gênero, raça, escolaridade, renda, índice de placa visível e variáveis relacionadas a hábitos de higiene bucal e conhecimentos de saúde bucal.

Inicialmente foi realizada a estatística descritiva dos dados por meio de frequência absoluta, percentual, intervalo de confiança a 95\% (IC95\%), médias e desvio padrão. Para as variáveis numéricas, inicialmente a normalidade da distribuição foi aferida através do teste Shapiro-Wilk. Após este processamento, os Testes $t$ de Student e ANOVA foram aplicados para os dados paramétricos, enquanto que o teste de Mann-Whitney foi utilizado para os dados não paramétricos. As variáveis categóricas foram analisadas através do Teste Exato de Fisher. Foi realizado também o teste de correlação de Spearman na análise de gravidade da doença periodontal. $O$ nível de significância adotado foi de $5 \%(p<0.05)$.

\section{Resultados}

Um total de 30 pacientes atendidos na Clínica Integrada da Universidade 
Ceuma, São Luís - MA (18 homens e 12 mulheres), com média de idade de 31,3 $\pm 10,6$ anos, representaram a amostra incluída neste estudo. Observou-se que a maioria dos indivíduos declara-se da raça negra (46,7\%). Com relação à escolaridade, o Ensino Médio Completo, Incompleto e Ensino Fundamental Completo representaram respectivamente $40,0 \%, 26,7 \%$ e $16,7 \%$ da amostra. A renda pessoal até um salário mínimo correspondeu a 66,7\% (Tabela 1).

A Tabela 2 expressa a distribuição da amostra de acordo com os critérios de diagnóstico clínico periodontal. A prevalência de gengivite no grupo estudado foi de $13,3 \%$, enquanto de periodontite crônica foi de $83,3 \%$. Com relação à extensão do comprometimento periodontal, se observou que $82,8 \%$ apresentavam doença periodontal na forma localizada e $17,2 \%$ na sua forma generalizada. Dentre os indivíduos diagnosticados com periodontite crônica $(\mathrm{N}=25)$, encontrou-se $56 \%, 24 \%$ e $20 \%$ correspondendo aos seus graus leve, moderado e avançado, respectivamente.

Em relação ao índice IPV, observouse maior valor $(56,8 \pm 23,9)$ no grupo com periodontite que no grupo com gengivite $(27,7 \pm 9,8)$, apresentando diferenças estatisticamente significantes.

No geral, encontrou-se no presente estudo, que a maioria dos indivíduos desconhecia placa bacteriana $(72,4 \%)$, gengivite e periodontite (72,4\%), tártaro/ cálculo dental (65,5\%), não sabia identificar uma escova dental com características ideais $(55,2 \%)$, nem o período correto para a substituição da escova dental (89,7\%). Observou-se também, que a maior parcela destes pacientes não utilizava antisséptico bucal $(58,6 \%)$ e não faziam o uso do fio dental $(65,5 \%)$. Na análise entre os grupos, apenas o conhecimento de gengivite e periodontite foi estatisticamente maior $(p=0,05)$ no grupo diagnosticado com gengivite $(75 \%)$ comparado ao de periodontite (20\%) (tabela 3$)$.

\section{Discussão}

No presente estudo, pôde- se observar a prevalência do sexo masculino, da raça/ cor negra, e uma média de 31,3 $\pm 10,6$ anos de idade. Com relação escolaridade, há uma maioria de pacientes com Ensino Médio completo $(40,0 \%)$ e que vivem com até um salário mínimo (66,7\%). Em um estudo que avaliou 0 conhecimento e 0 comportamento de 430 pacientes em atendimento nas clínicas de Endodontia e Dentística da Faculdade de Odontologia de São José dos Campos em relação à doença periodontal e higiene bucal, Choue colaboradores $^{9}$ observaram que $72 \%$ dos pacientes eram do gênero feminino, sendo predominante a faixa etária entre 41 a 50 anos.

Os resultados do presente estudo evidenciaram que os pacientes atendidos não tiveram um bom conhecimento sobre doenças peridontais, tendo um maior resultado negativo em conhecimentos sobre placa bacteriana (27,6\%), periodontite e gengivite $(27,6 \%)$ e, principalmente, sobre a troca correta da escova dental (44,8\%). Dovigoe colaboradores $^{10} \quad$ analisaram 0 conhecimento odontológico de adultos atendidos em uma Unidade de Saúde da cidade de São Carlos com uma amostra de 168 usuários maiores de 18 anos, e obtiveram resultado parecido: a pequena porcentagem de $24,4 \%$ dos usuários revelou saber o que é a doença da gengiva. Mas $80,36 \%$ responderam saber que a correta higienização bucal é importante para a saúde.

Outro resultado semelhante foi verificadopor Saliba, Unfer ${ }^{11}$. Emumestudo que avaliava o conhecimento popular e práticas cotidianas em saúde bucal, os autores utilizaram uma amostra estratificada de usuários que procuraram atendimento nas unidades sanitárias da zona urbana de Santa Maria, RS, encontraram um valor de $19,7 \%$ referenteà porcentagem de indivíduos da amostraque declararamconhecer as doenças 
Tabela 1 - Caracterização geral dos indivíduos incluídos no estudo (N=30)

\begin{tabular}{lccc}
\hline Variáveis & $\mathbf{n}$ & $\%$ & $\mathbf{( I C 9 5 \% )}$ \\
\hline Gênero & & & \\
$\quad$ Masculino & 18 & 60,0 & $(40,6-77,3)$ \\
$\quad$ Feminino & 12 & 40,0 & $(22,7-59,4)$ \\
Raça/ Cor da pele & 6 & 20,0 & $(28,3-65,7)$ \\
$\quad$ Branca & 10 & 33,3 & $(17,3-52,8)$ \\
Parda & 14 & 46,7 & $(7,7-38,6)$ \\
$\quad$ Negra & 2 & 6,7 & $(0,8-22,1)$ \\
Escolaridade & 5 & 16,7 & $(5,6-34,7)$ \\
$\quad$ Ensino Fundamental Incompleto & 8 & 26,7 & $(12,3-45,9)$ \\
$\quad$ Ensino Fundamental Completo & 12 & 40,0 & $(22,7-59,4)$ \\
$\quad$ Ensino Médio Incompleto & 2 & 6,7 & $(0,8-22,1)$ \\
$\quad$ Ensino Médio Completo & 1 & 3,3 & $(0,1-17,2)$ \\
$\quad$ Ensino Superior Incompleto & & & \\
$\quad$ Ensino Superior Completo & 4 & 13,3 & $(3,8-30,7)$ \\
Renda pessoal & 20 & 66,7 & $(47,2-82,7)$ \\
$\quad$ Sem renda & 6 & 20,0 & $(7,7-38,6)$ \\
$\quad$ Até um salário mínimo* & & & \\
Mais que um salário mínimo* & &
\end{tabular}

* Salário mínimo $(\mathrm{R} \$ 622,00)$

Tabela 2 - Distribuição da amostra de acordo com o diagnóstico clínico periodontal

\begin{tabular}{lccc}
\hline \multicolumn{1}{c}{ Variáveis } & $\mathbf{n}$ & $\%$ & $\mathbf{( I C 9 5 \% )}$ \\
\hline $\begin{array}{l}\text { Doença Periodontal (N=30) } \\
\quad \text { Ausente }\end{array}$ & 1 & 3,3 & $(0,1-17,2)$ \\
$\quad$ Gengivite & 4 & 13,3 & $(3,8-30,7)$ \\
$\quad$ Periodontite Crônica & 25 & 83,3 & $(65,3-94,4)$ \\
Extensão da Doença Periodontal (N=29) & & & \\
$\quad$ Localizada & 24 & 82,8 & $(64,2-94,2)$ \\
$\quad$ Generalizada & 5 & 17,2 & $(5,8-35,8)$ \\
Gravidade da Periodontite Crônica (N=25) & & & \\
$\quad$ Leve & 14 & 56,0 & $(34,9-75,6)$ \\
$\quad$ Moderada & 6 & 24,0 & $(9,4-45,1)$ \\
$\quad$ Avançada & 5 & 20,0 & $(6,8-40,7)$ \\
\hline
\end{tabular}


Tabela 3 - Distribuição absoluta e percentual da percepção dos indivíduos sobre higiene e conhecimentos de saúde bucal de acordo diagnóstico periodontal $(\mathrm{N}=29)$

\begin{tabular}{|c|c|c|c|c|c|c|c|c|}
\hline \multirow{3}{*}{ Variáveis } & \multicolumn{2}{|c|}{ Diagnóstico Periodontal } & \multirow{3}{*}{$p^{1}$} & \multicolumn{2}{|c|}{ Extensão } & \multirow{3}{*}{$\mathbf{p}^{\prime}$} & \multirow{2}{*}{\multicolumn{2}{|c|}{ Total }} \\
\hline & Gengivite & Periodontite & & Localizada & Generalizada & & & \\
\hline & $\%$ & $\%$ & & $\%$ & $\%$ & & $\mathbf{n}$ & $\%$ \\
\hline Conhecimento sobre & & & 0,30 & & & 0,57 & & \\
\hline Não & 50,0 & 76,0 & & 80,0 & 70,8 & & 21 & 72,4 \\
\hline $\operatorname{Sim}$ & 50,0 & 24,0 & & 20,0 & 29,2 & & 8 & 27,6 \\
\hline Conhecimento sobre & & & $0,05^{*}$ & & & 0,17 & & \\
\hline periodontite & 25,0 & 80,0 & & 100,0 & 66,7 & & 21 & 72.4 \\
\hline Sim & 75,0 & 20,0 & & 0 & 33,3 & & 8 & 27,6 \\
\hline Conhecimento sobre & & & 0,57 & & & 0,57 & & \\
\hline $\begin{array}{l}\text { tartaro/ calculo dental } \\
\text { Não }\end{array}$ & 75.0 & 64.0 & & 600 & 667 & & 19 & 65.5 \\
\hline Sim & 25,0 & 36,0 & & 40,0 & 33,3 & & 10 & 34,5 \\
\hline Conhecimento sobre & & & 0,22 & & & 0,60 & & \\
\hline $\begin{array}{l}\text { escova ideal } \\
\text { Não }\end{array}$ & & & & & & & & \\
\hline Sim & $\begin{array}{l}25,0 \\
75,0\end{array}$ & 60,0 & & 60,0 & 54,2 & & 16 & 55,2 \\
\hline Uso de Antisséptico & & & 0.55 & 40,0 & 45,8 & 032 & & \\
\hline Bucal & & & 0,03 & & & $0,0<$ & & \\
\hline Não & 50,0 & 60,0 & & 40,0 & 62,5 & & 17 & 58,6 \\
\hline $\mathrm{Sim}$ & 50,0 & 40,0 & & 60,0 & 37,5 & & 12 & 41,4 \\
\hline Uso de Fio Dental & & & 0,10 & & & 0,42 & & \\
\hline Não & 75,0 & 72,0 & & 80,0 & 62,5 & & 19 & 65,5 \\
\hline $\mathrm{Sim}$ & 25,0 & 28,0 & & 20,0 & 37,5 & & 10 & 34,5 \\
\hline Período correto para a & & & 0,62 & & & 0,44 & & \\
\hline Não & 100,0 & 88,0 & & 80,0 & 91,7 & & 26 & 89,7 \\
\hline Sim & 0 & 12,0 & & 20,0 & 8,3 & & 3 & 10,3 \\
\hline
\end{tabular}

periodontais.

Em estudo ${ }^{9}$ sobre nível de conhecimento de cárie, doença periodontal e medidas preventivas apresentadas pelos pacientes em tratamento na FOSJC:

Nível de conhecimento sobre cárie, doença periodontal e medidas preventivas apresentado pelos pacientes em tratamento na FOSJC, pesquisadores compararam o nível de conhecimento sobre cárie e doença periodontal e verificaram que aquele era maior, correspondendo, respectivamente, à porcentagem de $57 \%$ e $30 \%$. Constataram, também, que o uso de colutório e fio dental são recursos usados na higiene bucal por $15 \%$ e $63 \%$, dos indivíduos entrevistados, respectivamente. $\mathrm{Na}$ presente pesquisa foi constatado que $41,4 \%$ da amostra revelou usar enxaguatório bucal e 34,5\% da amostra se diz usuária de fio dental, demonstrando que, assim como no estudo da FOSJC, a maioria da população estudada não faz uso desses recursos de higiene bucal.

$\mathrm{Em}$ relação às doenças periodontais avaliadas (periodontite e gengivite), observou-se na presente pesquisa uma prevalência de periodontite crônica $(83,3 \%)$, sendo que, em relação à extensão, verificouse que a forma localizada era maioria $(82,8 \%)$. Da mesma forma, avaliando o perfil dos pacientes atendidos na clínica de Periodontia da EAP- ABO/ES, Medeiros e Rocha ${ }^{12}$ puderam concluir que se observou uma prevalência de periodontite crônica e uma menor prevalência na gengivite. Esses autores ressaltam, ainda, que em seu estudo não foi encontrada correlação entre o grau de escolaridade dos pacientes e o seu nível de conhecimento acerca de saúde bucal e periodontal, sua conscientização e motivação para a promoção da saúde (prevalência 
periodontite e gengivite). Resultado diferente do encontrado no estudo realizado por Dovigoe colaboradores ${ }^{10}$, já anteriormente citado, que observaram que os participantes da sua pesquisa com maior nível de escolaridade apresentaram mais conhecimento sobre doença periodontal, demonstrando que não há um consenso entre os autores sobre esse quesito na literatura.

\section{Conclusão}

Diante do exposto, pode-se concluir que os pacientes apresentam baixo conhecimento em relação às doenças periodontais e aos hábitos de higiene bucal. A respeito do diagnóstico periodontal, encontrou- se a prevalência da periodontite crônica nesse grupo. A participação do CD na educação, motivação e na prevenção das doenças bucais desses pacientes é imprescindível, necessitando, assim, receber mais atençãopor parte dos responsáveis pelo tratamento.

\section{Referências}

1. Gebran MP, Gebert APO. Controle químico e mecânico de placa bacteriana. Tuiuti: Ciência e Cultura. 2002;26(3):45-58.

2. Lang NP, Mombelli A, Attström R. Biofilmes e cálculos orais. In: Lindhe J, Lang NP, Karring $\mathrm{T}$. Tratado de periodontia clínica e implantodontia oral.5. ed. Rio de Janeiro: Guanabara Koogan; 2010. p. 271-291.

3. Eto FS, Raslan AS, Cortelli JR. Características microbianas na saúde e doença periodontal. Rev. biociênc. 2003;9(2):45-51.

4. Oliveira AFB, Passos IA, Paiva FPF et al. Aspectos clínicos e histológicos da gengiva: revisão de literatura. Odontologia Clín. Científ. 2005;4(2):95-100.

5. Dias LZS, Piol SAC, Almeida CSL. Atual classificação das doenças periodontais. U FES Rev. Odontol. 2006; 8(2):59-65.

6. Maehler M, Deliberator TM, Soares GMS et al. Doença periodontal e 
sua influência no controle metabólico do diabete. RSBO. 2011;8(2):211-8.

7. Abreu LMG, Lopes FF, Pereira AFV et al. Doença periodontal e condições sistêmicas: mecanismos de interação. Rev Pesq Saúde. 2010;11(2):52-6.

8. Santos PA, Rodrigues JÁ, Garcia PPNS. Conhecimento sobre prevenção de cárie e doença periodontal e comportamento de higiene bucal de professores de ensino fundamental. $\mathrm{Ci}$. enc. Odontol. Bras. 2003;6(1):67-74.

9. Chou TCA, Ferreira NS, Kubo CH. Avaliação do conhecimento e comportamento dos pacientes em tratamento odontológico em relação à cárie, doença periodontal e higiene bucal. RPG Rev Pós Grad. 2011;18(3):140-7.

10. Dovigo MRPN, Garcia PPNS, Campos JADB. Conhecimento odontológico de adultos atendidos em uma unidade de saúde da família do município de São Carlos, Brasil. Rev. odontol. Univ. Cid. São Paulo (Online). 2011;23(2).

11. Saliba O, Unfer B. Avaliação do conhecimento popular e práticas cotidianas em saúde bucal. Rev. Saúde Pública. 2000;34(2):190-5.

12. Medeiros UV, Rocha DS. Estudo epidemiológico da doença periodontal em pacientes adolescentes e adultos. UFES Rev. Odontol. 2006;8(2):19-28. 